\title{
IGLESIA Y CONFLICTOS SOCIALES EN LOS ANDES \\ $\mathrm{El}$ «indigenismo eclesiástico»
}

\author{
Imelda Vega-Centeno B.
}

"Si pues ha de ir al fuego eterno aquél a quien Cristo diga 'estuve desnudo y no me vestiste', ¿qué lugar tendrá en el fuego eterno aquél a quien diga 'estaba vestido y tú me desnudaste'?"

Bartolomé de Las Casas, Del único modo de atraer a las gentes a la religión verdadera, 1530.

EN UN TRABAJO ANTERIOR" nos hemos referido como "indigenismo eclesiástico" a la corriente de pensamiento y acción pro-indígena inspiradas en valores de justicia y solidaridad evangélicas, lideradas por autoridades o por representantes de la Iglesia. A propósito de esta expresión, algún lector, convertido en interlocutor, ha manifestado incomodidad o insatisfacción ante un intento de "caracterizar" cierta pastoral rural de obispos y sacerdotes de comienzos

- Publicado en Fernando Armas Asín (Comp.), La construcción de la Iglesia en los Andes (siglos XVI-XX), Fondo Editorial PUCP, Lima, 1999.

1 Imelda Vega-Centeno B., Pedro Pascual Farfán de los Godos: obispo de indios (1870-1945), IPA, Cusco, 1993. 
IMELDA VEGA-CENTENO B.

de siglo. Desde el punto de vista sociológico, sostenemos que la acción temporal expresada por la pastoral social de la Iglesia de todos los tiempos es posible de ser analizada y medida en los mismos términos que cualquier otro fenómeno social. La iglesia, como toda sociedad humana, es un hecho social, y la acción temporal de sus representantes institucionales, por mucho que esté animada por contenidos evangélicos, tiene una serie de implicaciones históricas, sociales y políticas posibles de ser estudiadas con los instrumentos de análisis de las ciencias sociales.

Pero, ¿de qué hablamos cuando nos referimos al indigenismo eclesiástico? No se trata del contagio de un ambiente indigenista del Cusco de los años 20, donde "hasta el obispo escribió cartas indigenistas", como señala un autor ${ }^{2}$, y los obispos no son "personajes inesperados" en la temática concerniente al indio, como señala otro autor ${ }^{3}$. El indigenismo eclesiástico que estudiamos forma parte de un fenómeno de larga duración, con sustento doctrinal propio, que se produce en el medio eclesiástico y que, en la importante coyuntura de generación de las ideas sociales modernas a comienzos de este siglo, resurgirá en la acción de notables prelados del mundo andino 4 .

En un reciente trabajo sobre el "indigenismo-2", M. Lauer 5 plantea una problemática similar a la de esta introducción: comprueba el autor que el llamado "movimiento indigenista" tiende a ser identificado con la vertiente socio-política del mismo, cuando el "movimiento indigenista" está formado por diversos procesos sociales, políticos, ideológicos y culturales que se desarrollan en períodos de diferente duración y que tienen diversos tipos de manifestaciones y representantes. Sería más correcto hablar de "los

2 José Tamayo Herrera, Historia del Indigenismo cusqueño, siglos XVIXX, INC, Lima, 1980, p. 282.

${ }^{3}$ Alberto Flores Galindo, "El horizonte utópico", en J.P. Delers e Y. SaintGeours (Comps), Estados y naciones en los Andes, Tomo II, Lima, IEP e IFEA, 1986, p.527.

${ }^{4}$ Estas hipótesis las aplicamos al estudio de un personaje clave de la época, Cf. I. Vega-Centeno, o.c., 1993.

${ }^{5}$ Mirko Lauer, Andes imaginarios: discursos del indigenismo-2, Lima, Centro Bartolomé de Las Casas y Sur, 1997. 


\section{IGLESIA Y CONFLICTOS SOCIALES EN LOS ANDES}

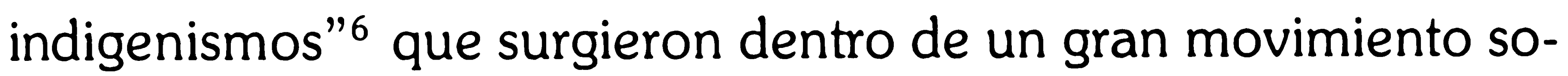
cio-cultural que produjo: debates, nuevas ideas sociales, expresiones artísticas, partidos políticos modernos, movimientos sociales y movimientos eclesiales, que, con ciertos elementos de inspiración común, dieron lugar a la génesis de las ideas sociales, y de los movimientos sociales más importantes en el Perú contemporáneo, para no hablar del indigenismo como origen de nuestras actuales ciencias sociales ${ }^{7}$.

Partimos pues del reconocimiento de la diversidad de realizaciones históricas que dio lugar el Movimiento Indigenista (ahora con mayúscula) y, para evitar el error epistemológico de "uniformar" a todos estos productos culturales bajo la percepción de su versión político-social, es preciso "apellidar" o "caracterizar" el aspecto del indigenismo que se quiere estudiar. Lauer optó por la poco poética denominación de "indigenismo-2" para llamar la atención sobre su sujeto de estudio y para diferenciarlo del indigenismo socio-político, que (inferimos) sería el "indigenismo-1", subrayando de esta manera los aspectos comunes y las diferencias que tenía el movimiento cultural de renovación estética y rescate de lo aborigen, con su par socio-político ${ }^{8}$.

En este contexto, entendemos por indigenismo el movimiento de reflexión sobre lo nacional que busca rescatar el carácter mestizo y autóctono de la joven república, reflexión que trata de plasmarse en medidas legislativas, educacionales, jurídicas, acción política, acción pastoral y propuesta estética. Movimiento de rescate de las raíces de lo nacional que se desarrolla en un ambiente polémico, en pleno auge del modernismo, del darwinismo social y racial, que "culpa" a la "desgraciada raza indígena" de todos los males del país, y muy en especial de la debacle bélica de $1879^{9}$.

${ }^{6}$ I. Vega-Centeno B., o.c., pp. 86-100.

${ }^{7}$ Imelda Vega-Centeno B., La construcción social de la sociología: invitación a la crítica, Lima, F. Ebert Ed., 1994, cap.1.

8 Mirko Lauer, o.c., p. 4.

9 Cf. Bibliografía sobre el indigenismo en nuestro trabajo de 1993; con respecto al auge del positivismo y el darwinismo social, Cf. Pilar García Jordán, Iglesia y poder en el Perú contemporáneo: 1821-1919, Cusco, CERA Bartolomé de las Casas, 1991; ver también nuestro "Pedro Pascual...", o.c., p. 62-65; 110-119. 


\section{IMELDA VEGA-CENTENO B.}

Con este trasfondo de ideas socio-históricas, el resurgimiento de la figura del indio como preocupación central en la pastoral de la Iglesia católica en los Andes reactivará los orígenes de su fundamentación doctrinal. En el trabajo anterior señalamos que las fuentes propias que alimentan el indigenismo eclesiástico son: a) la tradición eclesiástica de protección de indios del frente indiófilo, b) la naciente reflexión teológica sobre la dignidad humana, y c) la práctica permanente de los obispos defensores de indios a lo largo de todo el período colonial, que permanece en la joven república ${ }^{10}$.

Como demostramos entonces, la fundamentación doctrinal de la práctica indigenista de los agentes eclesiales difiere completamente de los fundamentos políticos del Comité Pro-Derecho Indígena Tahuantinsuyo, por ejemplo (de neta inspiración marxista); por ello, su vocabulario, las medidas prácticas que proponen y las realizaciones que llevan a cabo tienen más referencias a los discursos de los sacerdotes del frente indiófilo, a la vigencia del espíritu lascasiano en la Iglesia peruana que a los encendidos discursos políticos del naciente socialismo. Una de las dificultades objetivas para la confluencia eficaz entre los objetivos comunes del indigenismo político-social y el indigenismo eclesiástico fue justamente la impermeabilidad entre ambos discursos. Ambos se leyeron de forma antagónica, y fueron voluntariamente enfrentados con objetivos políticos, cuando (objetivamente) defendían causas comunes ${ }^{11}$.

En el presente trabajo proponemos una indagación en torno al fenómeno del indigenismo eclesiástico desde sus orígenes a través de la pervivencia del espíritu lascasiano que animó al frente indiófilo, su reactivación dentro del debate en torno a lo nacional después de la guerra del Pacífico, un acercamiento a las más importantes figuras de su período característico y su pervivencia en la acción pastoral de la Iglesia en los Andes peruanos hasta nuestros días.

10 I. Vega-Centeno B., o.c., p.101-109.

11 I. Vega-Centeno B., o.c., p. 177. 


\section{IGLESIA Y CONFLICTOS SOCIALES EN LOS ANDES}

\section{El fRENTE INDiófilo y El espíritu lascasiano en el Perú}

Un acucioso investigador sobre el P. Bartolomé de Las Casas sintetiza en torno a cinco puntos fundamentales el carácter del espíritu lascasiano ${ }^{12}: 1^{\circ}$ ) la acción evangelizadora ha de ser persuasiva $y$ amorosa, ya que es el único modo como enseñó Cristo mismo, $2^{\circ}$ ) la acción catequética debe instruir suficientemente a los indios, los que accederán al bautismo sólo si este proceso se ha realizado, $3^{\circ}$ ) la acción profética, es decir, el uso de la apología sólo se hará cuando lo exijan las circunstancias, la evangelización debe ser pacífica, $4^{\circ}$ ) las guerras de conquista son inaceptables por principio, por ser todas ellas injustas y porque utilizan formas antievangélicas de trato con los indios, y $5^{\circ}$ ) tanto las encomiendas como los repartimientos son inaceptables, puesto que se fundan en la opresión de los indios y son un impedimento para que estos acepten libremente el evangelio.

Como podemos comprobar, Las Casas es un defensor de la igualdad entre todos los seres humanos, por ello, parte de su Apologética está destinada a demostrar la plená condición humana de los indios, así como a defender la libertad de todos los seres humanos, creados por Dios para ser libres, puesto que "Dios a nadie hizo esclavo" 13 . En su rechazo de la guerra para dominar a las naciones indígenas, exige además la "restitución de todo lo que los españoles han robado" (Memorial al Consejo de Indias, 1565), obligación que es condición para salvación de los propios españoles. Fray Bartolomé llevó hasta sus últimas consecuencias la tradicional doctrina sobre la restitución, que tenía varios siglos de vigencia en la Iglesia y que en el contexto histórico de la guerra de la conquista adquiere actualidad y urgencia excepcionales. Otro aspecto fundamental de esta doctrina es la defensa de la autoridad que surge de la voluntad del

${ }^{12}$ Isacio Pérez Fernández, Bartolomé de Las Casas en el Perú: 1531-1573, Cusco, CERA Bartolomé de las Casas, 1988, p. 2-3.

13 Gustavo Gutiérrez, «¿Quién es el indio? La perspectiva teológica de Bartolomé de Las Casas", en J.O. Beozzo, et. Al., La Iglesia y los indios: ¿500 años de diálogo o de agresión?, Quito, Colección 500 años, Ed. Abya Yala, 1990, p. 123-140, p. 129. 


\section{IMELDA VEGA-CENTENO B.}

pueblo, de modo que Las Casas insistirá en la idea de que a los españoles no les es lícito asumir un papel de autoridad en las Indias, si la legitimidad de la misma no ha emanado de la voluntad de los indios ${ }^{14}$.

Exigiendo el cumplimiento de esta doctrina, Las Casas subraya que no sólo está en cuestión el tema de la salvación de los indios, sino el de la salvación de los españoles, pues la situación de opresión de los indígenas es un pecado que clama al cielo; la famosa frase "más vale un indio infiel pero vivo, que un indio cristiano, pero muerto", subrayará dramáticamente el valor absoluto de la vida humana como don de Dios. A su partida para España, recordará aún que el Cristo mil veces azotado, afligido y abofeteado queda en las Indias, pues según la teología lascasiana el indio no es un cristiano más, sino el otro Cristo, el pobre según el evangelio ${ }^{15}$.

Este espíritu lascasiano es el que se difundió en el Perú, aunque Las Casas nunca hubiera llegado a estas tierras: tanto por la difusión de su obra y por las leyes que logró hacer promulgar por la Corona como por la difusión social de las ideas de los dominicos de la Española (de los cuales él mismo era heredero y portavoz). Por estas razones, con Pérez Fernández podemos decir que el espíritu lascasiano marcó la pauta del proceso histórico de la evangelización efectiva en el Perú, aunque no consiguiera que estos principios se encarnaran completamente, aunque no lograra plenamente sus objetivos, quizás lo que sí consiguió fue "aplacar la violencia del espíritu conquistador y la opresión del espíritu de conquista". La disminución de la violencia dirigida hacia el indio fue efecto de la acción profética del espíritu lascasiano en el Perú, su marca en el proceso de evangelización estará dada por la relevancia de la acción catequética y de la acción profética: pues el anuncio del evangelio no puede ser el vehículo de destrucción de las personas de los indios ${ }^{16}$.

\footnotetext{
14 Ib., o.c., p.130-131.

15 Ib., o.c., p. 135-140.

16 Ib., o.c., p. 6-12.
} 


\section{IGLESIA Y CONFLICTOS SOCIALES EN LOS ANDES}

Ya los dominicos de la Española habían desarrollado el principio tradicional de la teología sacramental sobre la necesidad de la restitución de lo usurpado abusivamente, para que pueda ser válido el sacramento. Las Casas hará de este tema un leitmotiv y los sacerdotes del frente indiófilo lo asumirán como elemento fundamental de la práctica sacramental de los evangelizadores en el Nuevo Mundo. Este espíritu deberá impregnar la acción evangelizadora: profética, catequética, sacramental, civilizadora-benéfica y cultural ${ }^{17}$.

Una prueba de la influencia efectiva del espíritu lascasiano en el Perú es el reconocimiento que hace de este hecho uno de sus principales y más ardientes detractores, el Parecer de Yucay o Anónimo de Yucay (1571). El autor anónimo lamenta la influencia de los escritos de Las Casas, inclusive en él mismo, pero sobre todo a lo largo de las Indias y en la política desarrollada por la Corona. Partiendo de este hecho, intenta refutar las tesis centrales de Las Casas, responsabilizando a "un solo hombre" (106) de todos los "errores cometidos y difundidos"18. Pero, como señala Pérez Fernández, "Las Casas dejó de estar solo y se convirtió en multitud desde 1552", cuando las autoridades de las Indias ejecutaban las Leyes Nuevas y eran traídos al Perú por el propio provincial de los dominicos los ejemplares de los Ocho tratados que acababa de imprimir el P. Las Casas en España (1552-1553) ${ }^{19}$.

Aunque se pueden "rastrear" huellas del espíritu lascasiano en el Perú en documentos anteriores a estas fechas, es desde entonces que la recurrencia de su temática, argumentación, fundamentación doctrinal y medidas sugeridas para corregir los problemas resultan sumamente frecuentes en el discurso de religiosos de diversas congregaciones, así como en el de los obispos. Se encuen-

17 Ib., o.c., p. 12.

${ }^{18}$ Gustavo Gutiérrez, o.c., pp. 56-60. Ver también, Lewis Hanke, La lucha por la justicia en la conquista de América, Madrid, [Buenos Aires, 1949], Ed. Itsmo, 1992.

19 Isacio Pérez Fernández, El anónimo de Yucay frente a Bartolomé de Las Casas. Edición crítica del Parecer de Yucay (1571), Cusco, CERA Bartolomé de las Casas, 1997. p.177. 


\section{IMELDA VEGA-CENTENO B.}

tran con frecuencia denuncias de los agravios y malos tratos de los españoles para con los indios, el recurso en la predicación y la catequesis a la doctrina de la restitución como condición para la validez de los sacramentos y la argumentación en torno a la negación de la efectividad del título de dominio del rey de España sobre las Indias, por haberse impuesto a través de los sistemas inaceptables de la guerra de conquista y de las encomiendas ${ }^{20}$.

Desde entonces se elevaron diversas voces contra los abusos cometidos contra los indios. En 1565, los franciscanos se pronuncian contra la mita y el sistema de servidumbre personal, el arzobispo Loaiza, en 1564 , se pronuncia contra los corregimientos de indios, el Segundo Concilio Limense (1567), en sus "Actas", exhorta a los españoles a que "cese la opresión contra los indios y que se les restituya lo robado", y a los sacerdotes se les exhorta a no aceptar donaciones de bienes que son fruto de la opresión. Aunque este concilio se realiza cuando Las Casas ya ha muerto, muchos hablan de que tuvo una influencia directa sobre el mismo. Por otro lado, la relación entre Las Casas y fray Alonso de Maldonado era cierta, y sus resultados se pueden comprobar en el contenido de los Cinco memoriales que escribió aquél entre 1558 y 1566; inclusive sus opositores ideológicos, como el Memorial de Sánchez (1566), muestran familiaridad con los escritos de Las Casas, aunque estén escritos para marcar sus diferer.cias en cuanto al trato a los indígenas se refiere ${ }^{21}$.

La eficaz acción del "espíritu gris de Toledo" y sus reformas a sangre y fuego "fue la subversión del espíritu lascasiano en las Indias y en España", según Pérez Fernández; lo cierto es que el virrey Toledo no sólo recogió y desapareció las obras de Las Casas, sino que combatió los efectos de las Leyes Nuevas y de la encarnación del espíritu lascasiano en el Perú. Sin embargo, el espíritu lascasiano siguió influyendo de modo anónimo a través de los logros conseguidos, por la dinámica de cambios y de toma de conciencia sobre la dignidad humana que habían desencadenado, por el vigor evangélico que suscitó en los religiosos y obispos, $e$

${ }^{20} \mathrm{Ib} .$, o.c., p. 264.

${ }^{21}$ I. Pérez Fernández, 1988, o.c., p.351-412; p. 590-628. 


\section{IGLESIA Y CONFLICTOS SOCIALES EN LOS ANDES}

inclusive, por la recurrencia de los males a los que Las Casas quiso dar remedio ${ }^{22}$.

A pesar del vigor de la prédica lascasiana, la puesta en práctica de su espíritu durante la Colonia frecuentemente redujo al indio a la condición de menor de edad, sujeto de "protección paternal", pero no sujeto pleno de derechos; esta actitud no fue ajena a los representantes de la Iglesia, que, imbuidos de una doctrina de la misericordia, reclamaron clemencia y atención para el indio sin que ésta conllevase el reconocimiento del mismo como sujeto pleno de derechos.

\section{DesPuÉs DE LA DEBACLE BÉLICA: EL INDIO Y LA DEFINICIÓN DE "LO NACIONAL"}

En las condiciones socioculturales del inicio de la república, con una sociedad peruana casi analfabeta y muy pocas vías de comunicación, la Iglesia y el púlpito jugaban un papel cohesionador, de comunicación y de representatividad del poder civil que no se podían descuidar; a su vez, las diversidades étnicas y geográficas resaltaban más aún el papel de la Iglesia como referente social e histórico ${ }^{23}$. La sociedad poscolonial, inmovilizada frente a las grandes tareas que le correspondían, se refugió en el providencialismo y el fatalismo como justificativos para su incapacidad de respuesta frente a la definición y construcción de lo nacional. La crítica liberal se centrará en cierta imagen parasitaria del cura, asociado con el gamonal en la explotación del indígena, culpándolo del atraso social del país y de vivir a expensas de la superstición y la ignorancia del pueblo ${ }^{24}$.

En este ambiente decimonónico, algunos pensadores costeños comienzan a envidiar al mundo anglosajón, tomándolo como modelo de organización social y económica, sinónimo del progreso, estabilidad política, homogeneidad social y racial; la influencia

22 I. Pérez Fernández, 1988, o.c., p. 517.

23 Jeffrey Klaiber, La Iglesia en el Perú, Lima, Fondo Editorial PUCP, 1988, p. 239; P. García Jordán, 1991, o.c., p. 53; I. Vega-Centeno B., 1993, o.c., p. 59 ss.

24 J. Klaiber, o.c., p 239-240. 


\section{IMELDA VEGA-CENTENO B.}

de las tesis evolucionistas y del darwinismo social servirán para justificar la opresión de los indios y las "otras razas", lo que los llevará a reinterpretar la historia del Perú de manera que los indios resultaban ser el obstáculo para el progreso e integración nacionales, y también de la debacle bélica en la Guerra del Pacífico; por ello había que contribuir a la desaparición progresiva de las razas inferiores (en este caso, los indígenas) por la selección natural a través del mestizaje con los anglosajones ${ }^{25}$. Sobresale en esta línea Pazos Varela, que, en sus Tesis sobre la inmigración en el Perú, afirma que: a) la raza indígena es por naturaleza y cultura una raza inferior e incapaz de progreso, y b) que las razas cruzadas o puras constituían la verdadera población del país, pero estaban debilitadas por el tiempo. H. Fuentes propone por estas razones que, en lugar de traer chinos, se traigan blancos norteamericanos, pues el cruce con ellos significaría estabilidad, orden y progreso ${ }^{26}$.

Las teorías europeas sobre la pureza y degeneración de las razas adquieren un tinte "científico", alimentadas por el darwinismo aplicado a lo social, y darán sustento al racismo de la sociedad peruana poscolonial, ejemplo de ello es el estudio de $\mathrm{H}$. Unanue sobre los efectos del clima en las diferentes razas humanas (1809), pero más recalcitrante es C. Palma (1897), para quien en la lucha por la supervivencia de los mejor dotados tanto los indígenas como los chinos desaparecerían por el efecto del avance de la civilización; por esta razón, la educación del indígena preconizada por los "progresistas" de la época le parecía absolutamente innecesaria ${ }^{27}$.

Los ensayos fallidos de inmigraciones europeas, la decadencia del darwinismo y del evolucionismo y la progresiva pérdida de entusiasmo de los positivistas provocarán la reacción "espiritualista", que propone redescubrir la historia pasada para encontrar las soluciones al presente. A. Deustua inicia esta vía, que posteriormente revitalizarán J. de la Riva Agüero y V.A. Belaúnde. El "rescate" de lo indígena de esta posición tiene que ver más con el sentido práctico de no disponer de otra mano de obra para los

25 I. Vega-Centeno B., 1993, o.c., p. 60.

${ }^{26}$ Citados por P. García Jordán, o.c., p. 251-253.

${ }^{27}$ Ib., p. 251-255; ver también I. Vega-Centeno, 1993, o.c. p. 58-62. 


\section{IGLESIA Y CONFLICTOS SOCIALES EN LOS ANDES}

rudos trabajos que requería el país para salir de su aislamiento y retraso que con una defensa de los indígenas, tal como la entenderíamos hoy. Con estos argumentos, la educación e incorporación del indígena a la vida nacional serán reflexiones que darán vigencia y cierta "mística" a una nueva etapa de explotación del indio hacia fines del siglo XIX ${ }^{28}$.

En este contexto, la Iglesia jugó un triple papel: defensora de los indios frente al gobierno, portavoz del poder civil frente a los indios sublevados y árbitro entre autoridades y campesinos. Cohesionadora de la sociedad peruana, propagandista ideológica contra los proyectos de "sajonización" (que eran vistos como avance del protestantismo), avanzada de la civilización frente a los indígenas del oriente, regidora de los actos cotidianos $A$ fines del siglo XIX la Iglesia fue consolidando su posición dentro de la sociedad peruana con un poder y autonomía de que no gozó anteriormente ${ }^{29}$.

Desde 1596, los obispos peruanos habían obtenido el título de protectores de indios por derecho propio a su función pastoral, función que la Corona tuvo que aceptar. En la pauta de los concilios limenses (segundo y tercero), los obispos peruanos se perfilarán en la línea de los protectores que, aunque no hayan llegado a poseer la intransigencia evangélica de un Las Casas, llevaron a cabo una intensa labor espiritual y apostólica, superando las excomuniones y los alguaciles de otros tiempos. Una notable figura de esta tradición es santo Toribio de Mogrovejo, obispo de Lima, que benefició a los indígenas a través de la reforma del clero y las doctrinas, que conoció de sus sufrimientos y buscó darles remedio inmediato a través de sus incansables visitas pastorales. La visita pastoral era una institución que permitía al obispo entrar en contacto directo con la realidad de sus más lejanas doctrinas, aunque ornadas con el estilo vaticano, en estas visitas los obispos se hospedaban en las casas curales, dormían en las chozas de los indios, podían revisar los libros parroquiales y comprobar el estado sacra-

28 P. García Jordán, o.c., p. 256; I. Vega-Centeno, o.c., p. 61-62.

29 P. García Jordán, o.c., p.263, 317; J. Klaiber, 1988, o.c., pp. 298-273; I. Vega-Centeno, o.c., 62. 
IMELDA VEGA-CENTENO B.

mental y catecumenal de sus fieles. Recorridos largos, penosos, que permitían un contacto real con el indígena y su situación de explotación, condición que produjo no pocas "conversiones" episcopales, como la de Vasco de Quiroga, Mons. de Landa y la del propio santo Toribio de Mogrovejo ${ }^{30}$.

La escasez de clero, su debilidad moral y deficiente formación, así como su relación con las cada vez más frecuentes revueltas campesinas, preocupaban mucho a la Iglesia peruana de los albores del siglo XX; la situación del indígena, su educación y la necesidad de intermediación de éste con las autoridades civiles por parte de la Iglesia serán temas que preocuparán a las asambleas episcopales del período. En 1903 se aceptó la venida de clero extranjero para revigorizar la Iglesia, sin embargo ésta quedaba muy supeditada aún al Estado por la vigencia del Patronato y por su dependencia económica ${ }^{31}$.

Algunos temas "conflictivos" en la relación de la Iglesia con el Estado en este período son los generados en torno a la nueva legislación sobre la tolerancia de cultos y la creación de las escuelas adventistas en el altiplano, ambas normas quitaron el monopolio ideológico de la Iglesia católica en el campo de la educación y la difusión de las ideas. La secularización de los cementerios y el matrimonio civil limitan más aún su esfera de influencia, pero su defensa del derecho a la educación del indígena, la impugnación de los tributos excesivos que debían pagar los indios y el combate contra todas las formas de trabajo servil de éstos acrecentaron su autonomía relativa frente al poder estatal ${ }^{32}$.

Ya en 1849, un debate entre el P. B. Herrera y el diputado P. Gálvez muestra el papel de defensa de la Iglesia del derecho al sufragio de los indios, aunque finalmente venció la posición de Gálvez. Mons. J.A. Huerta, obispo de Puno, insistirá en la necesidad de escuelas parroquiales para la educación del indígena (1877); durante la rebelión de Huaraz, el P. Fidel Olivas Escudero jugará un importante papel mediador evitando mayores derramamientos de sangre (1885). Bajo la influencia de la encíclica Rerum nova-

30 I. Vega-Centeno, 1993, o.c., pp. 109-110.

31 Ib., p. 62.

32 Ib., p. 116 y ss; P. García Jordán, o.c., p. 248. 


\section{IGLESIA Y CONFLICTOS SOCIALES EN LOS ANDES}

rum (1891), el Concilio Plenario Latinoamericano de 1899 hablará de la necesidad de educar al indígena, y la asamblea episcopal peruana de 1902 urgirá en torno a las necesidades de educación del indio y el papel de los párrocos en la misma. En 1905 el obispo de Huaraz criticará duramente la leva forzosa de los indios, lo cual no contribuye a que éste se identifique con la nación. Por su parte, Mons. P.P. Drinot, durante su episcopado en Huánuco, se preocupará repetidamente de la situación del indígena, propiciando medidas de protección y de defensa ${ }^{33}$.

A inicios del siglo XX, la Iglesia peruana es aún símbolo de unión nacional. Aunque ha disminuido su convocatoria, es una vigorosa defensora de los fueros de la Iglesia, pero con muy poca iniciativa pastoral. En el VII Concilio Limense de 1917 se reúnen notables obispos como Mons. Holguín (Arequipa), Mons. Farfán (Huaraz), Olivas Escudero (Ayacucho) y Drinot (Huancavelica), todos ellos distinguidos por su defensa de los indios y por su participación en las luchas regionales contra el asfixiante centralismo limeño que emana de todo el aparato estatal. La reflexión episcopal de este concilio está enmarcada dentro de la lucha vaticana contra el liberalismo y el positivismo, la defensa de la jornada de trabajo de ocho horas y los planteamientos papales sobre "la cuestión obrera" (1891), además de la Carta del Papa a los obispos latinoamericanos sobre la cuestión indígena en el continente (1912). Por estas razones, no son de extrañar sus exhortaciones:

"A los hacendados y mineros, a los patrones, acuérdense de los indígenas, que en su provecho cultivan los campos con el sudor de su frente, (...) ellos son hijos de Nuestro Señor Jesucristo lo mismo que los patrones, por lo cual los exhortamos encarecidamente, amenazándolos con la ira de Dios, a que traten con cariño, reconozcan y protejan sus derechos (...) les abonen por su trabajo el salario correspondiente, expliquen con libertad la gravedad del

33 Cf. J. Dammert, "La pastoral social y el mundo campesino", en CEAS, Evangelización y pastoral social: avances y perspectivas. Simposium por los XXV años de la Comisión Episcopal de Acción Social, CEAS, Lima, Ceas Ed., 1991, p. 169-183; J. Klaiber, o.c. 124, 271; Jeffrey Klaiber, Religión y revolución en el Perú: 1824-1976, Lima, Universidad del Pacífico Ed., 1980, pp. 83-92. 


\section{IMELDA VEGA-CENTENO B.}

pecado contra la justicia y la caridad que cometen aquellos que convierten a los indígenas en verdaderos esclavos, les niegan el salario estipulado o los explotan despiadadamente"34.

En este período, y en reacción contra las ideas racistas y excluyentes hacia lo indígena como fundamento de lo nacional, se madura, tanto en los sectores intelectuales, sociales, artísticos, políticos, como eclesiales, el importantísimo movimiento social y de ideas al que hemos llamado indigenismo, el cual tendrá exponentes muy connotados en la generación de 1909, en los nacientes partidos políticos modernos en la década del veinte, en los comités pro-defensa del indígena y en el grupo más importante de obispos que forman parte del indigenismo eclesiástico, tal como lo definimos en nuestra introducción ${ }^{35}$.

\section{Auge DEL INDIGENISMO ECLESIÁSTICO: 1900-1930}

La primera figura que caracteriza este período es la de Mons. Fidel Olivas Escudero, quien, siendo aún sacerdote en la diócesis de Huaraz, juega un importante papel de mediador durante la rebelión indígena de Atusparia y Ucchu Pedro en 1885. Cuidadoso de su papel, trató de no parcializarse hacia ninguno de los bandos en pugna, calmando ánimos y evitando mayores derramamientos de sangre $^{36}$. Elevado a la dignidad episcopal, como obispo de Ayacucho destacó en la línea de los obispos protectores de indios; en un sermón de 1900 dice:

"El corazón menos sensible se conmueve al ver la tristísima condición de multitud de indios en los pueblos de interior, que forman la mayoría de la república, envueltos en la más crasa ignorancia de sus derechos" 37 .

34 Actas del VI Concilio Limense, 1917; I. Vega-Centeno, 1993, o.c., p. 111-112.

${ }^{35}$ Ver bibliografía sobre el Indigenismo y la génesis de este proceso en nuestro Pedro Pascual... o.c., 1993.

36 Fidel Olivas Escudero, Obras, Seis Tomos, Lima, Imprenta La Rosa \& Co., 1911; Tomo II, p. 276.

37 F. Olivas Escudero, o.c., Tomo II, p. 167-168. 


\section{IGLESIA Y CONFLICTOS SOCIALES EN LOS ANDES}

Esta situación lo obliga a hacer la siguiente exhortación a los sacerdotes:

"En virtud de vuestro sagrado ministerio sois padres, pastores del pueblo, estáis llamados a regenerar a esos pobres desgraciados, brindándoles protección decidida y eficaz, mediante la fundación de escuelas parroquiales".

Exhortación que lo coloca en la línea de las disposiciones del Concilio Plenario Latinoamericano de 1899, que hizo el mismo llamado, el cual fue retomado por la Asamblea Episcopal Peruana de 1902 (Acuerdo $n^{\circ} 4$ ).

En su carta pastoral con motivo de la toma de posesión de la diócesis de Ayacucho, Mons. Olivas Escudero afirmará con vigor:

"Los pobres son, pues, patrimonio de los obispos y su gloria constante, según la expresión de san Jerónimo (...). Los Padres del tridentino, fieles intérpretes de la Iglesia, le imponen terminantemente este deber, de modo que los pobres han de ser la pupila de los ojos del obispo"38.

Si en la anterior referencia podría chocar a nuestros oídos modernos que se llame "desgraciados" a los indios, Mons. Olivas Escudero no está haciendo otra cosa que usar el término castizo apropiado, pues los indios están privados de la gracia al estar sometidos a una tristísima condición que los priva de todos sus derechos. Como obispo protector de indios, hace la opción preferencial por los mismos, por los pobres según el evangelio, ellos son su patrimonio, su heredad, como diría el salmista.

En una línea pastoral que se aproxima evidentemente al espíritu lascasiano del frente indiófilo, Mons. Olivas Escudero destaca la figura y enseñanzas de santo Toribio de Mogrovejo, dedicando a su memoria y a la de sus incansables recorridos pastorales a lo largo de su diócesis hermosas páginas en las que se destaca no

38 F. Olivas Escudero, o.c., Tomo IV, p. 13-14. 
IMELDA VEGA-CENTENO B.

sólo su conocimiento de la historia de la iglesia en el Perú, sino las enseñanzas espirituales y pastorales que el testimonio del ilustre obispo de Lima dejó a sus hermanos en el episcopado ${ }^{39}$. No deja de ser interesante que, en el mismo período, otro destacado representante del indigenismo eclesiástico, entonces sacerdote de la diócesis de Cusco, escribiera un hermoso homenaje a santo Toribio, modelo de dedicación pastoral, y de los obispos protectores de indios ${ }^{40}$.

Sería interesante poder trabajar comparativamente la reflexión y acción pastoral del grupo de obispos que formaban parte del frente indiófilo dentro de la Asamblea Episcopal peruana de comienzos de siglo, las Obras de Mons Olivas Escudero están publicadas hasta 1911, y el resto de su producción está dispersa en las publicaciones de la época; igualmente los escritos de Mons. Drinot, en su período de obispo de Huánuco; previamente la preocupación pastoral por la situación de los indios en el altiplano puneño fue destacada por Mons. J.A. Huerta, labor que fue interrumpida bruscamente a consecuencias de su enfrentamiento con el Gobierno por la realización y publicación del $1^{\circ}$ Sínodo $\mathrm{Pu}$ nense (1868), asamblea que advirtió a "los comerciantes que obliguen al indio a venderles sus mercancías cometerán pecado grave, cuya absolución queda reservada al diocesano" 41 . Nosotros hemos tenido posibilidad de investigar en los escritos, archivos departamentales de la arquidiócesis, archivo del fuero agrario, bibliotecas y memoria familiar del más destacado de sus representantes, Mons. Pedro Pascual Farfán de los Godos ${ }^{42}$; por ello el presente esbozo analítico estará ligado a dicho trabajo de largo aliento.

39 F. Olivas Escudero, o.c., Tomo IV, p. 289-307.

40 Pedro Pascual Farfán; Solio de santo Toribio, Homenaje al III centenario de la muerte de santo Toribio, Cusco, Tipografía Espinar, 1905.

41 Juan Ambrosio Huerta, obispo de Puno, Constituciones del $1^{\circ}$ Sínodo Diocesano Punense, celebrado en la Iglesia de San Carlos en el año de 1868, Imprenta de la Iglesia Puneña, 1868; IBID, Obras, Tres tomos, Tip. Americana, 1906, o.c., Tomo III, p. 72-73.

42 I. Vega-Centeno, 1993, o.c. 
IGLESIA Y CONFLICTOS SOCIALES EN LOS ANDES

\section{a) Una acción pastoral indigenista}

Desde el comienzo de su episcopado en Huaraz (1908), Mons. Farfán desarrollará una incansable labor de contacto directo con los más alejados pueblos de su diócesis. Sus incansables visitas pastorales le permiten llegar a lugares donde el obispo anterior que las había visitado había sido Mons. de la Reguera, en 1789, o Mons. Morcillo Rubio, en 1780. Este afán de entrar en contacto directo con las necesidades de su diócesis le hace percibir la urgencia de formar sacerdotes que tengan conocimiento del quechua y de las necesidades concretas del hombre andino; estas serán las preocupaciones pastorales que llevará a las asambleas episcopales de 1912 y 1917. Una vez en la diócesis de Cusco (1918-1933), desarrollará intensamente estas intuiciones iniciales, marcando constantemente la vida de la diócesis con la reflexión de sus cartas pastorales, que retoman los acontecimientos eclesiales, nacionales e internacionales de la época, acompañando la reflexión teológica y pastoral con actos de compromiso con la historia ${ }^{43}$.

Dos cartas pastorales detienen nuestra atención, pues están directamente relacionadas con la situación del indígena. La primera, escrita en quechua el 19 de julio de 1918, dirigida a los indios de la diócesis; la segunda, de junio de 1920, sobre la "protección de la raza indígena". La primera es la única carta pastoral con destinatarios precisos, distintos de la pastoral dirigida a todos los fieles con motivo de su traslado de sede episcopal. Esta carta es sumamente paternal y desborda de ternura hacia los indios, subrayando la predilección de la Iglesia hacia éstos, en los mismos términos de la carta sobre la condición de los indios latinoamericanos de Pío X (7-VI-1912) ${ }^{44}$.

La segunda carta pastoral (1920) habla de la "gran obra nacional del día, que es la protección, el resurgimiento de la raza indígena: de nuestra raza, de nuestros abuelos, los dueños del Perú". Al reivindicar el tema, como sujeto de preocupación especial del

43 Ib., p. 134-137.

44 Estas dos cartas pastorales figuran como anexos a nuestro Pedro Pascual... o.c., pp. 203-229. 


\section{IMELDA VEGA-CENTENO B.}

obispo, afirma: "La causa del indio en el Perú, principalmente en el Cusco, es y debe ser la causa propia del obispo". Opción preferencial que se aproxima al sentido de la expresión de Mons. Olivas Escudero de los indios como "patrimonio, pupila de los ojos del obispo". Para Mons. Farfán no sólo los indios son demográficamente el contingente humano más importante de su diócesis, sino que son los más desprovistos de los beneficios de la civilización, por ello tienen que estar sujetos a la protección especial del obispo. La "regeneración" de los indios es más urgente en cuanto se vive un período de revueltas campesinas en todo el país, que en la región surandina son más frecuentes aún, y que se han expresado con no poca violencia; con una mezcla de profetismo, preocupación pastoral y sincero temor, ve acercarse un "torrente que se desborda al abismo", pues los indios son conscientes de haber sido despojados de sus tierras y de estar sometidos a un régimen de vida miserable. Su llamado se dirige a la Iglesia, para que cumpla el papel de protectora de indios, y a los cristianos para que, actuando en justicia según las exigencias de su fe, logren conjurar el peligro de estallidos sociales con consecuencias imprevisibles ${ }^{45}$.

La evocación de situaciones extremas de explotación, sea a través de la leva forzosa, la servidumbre o "pongaje", la ley de Circunscripción Vial o la Ley de Vagancia demuestran su profundo conocimiento de la situación del indio en el Sur Andino, y de las cargas que asimétricamente se acumulan sobre él a nombre de la "patria". Esta carta fue sumamente controvertida, no sólo en Cusco, sino que provocará la reacción del nuncio apostólico, quien epistolarmente le advierte que en "su ingenua generosidad" está "haciendo creer a los indios que las tierras les pertenecen", cuando como obispo debía enseñarles la obediencia. Su respuesta (1921) a esta amonestación es enérgica, defiende su fuero episcopal, pues afirma no haberse excedido del mismo relatando las situaciones de "extremo abuso de los indios" que él personalmente ha podido comprobar. Al afirmar el carácter pastoral de su carta, Mons. Farfán responde al nuncio diciendo que podría añadir sin fin de datos 


\section{IGLESIA Y CONFLICTOS SOCIALES EN LOS ANDES}

objetivos de la realidad, los que fundamentarían con mayor contundencia las preocupaciones pastorales que en dicha carta pastoral ha expresado ${ }^{46}$.

Aprovecha la oportunidad para enumerar la inmensa tarea pastoral que debiera realizar la Iglesia a favor de los indios, y que se ve incapacitada de hacerlo por falta de personal apropiado y de medios económicos. Subrayando su opción pastoral por los indios dirá aún: «Con ingenuidad, pero sin temor a equivocarme puedo decir que el clero en el tiempo de la patria no ha cumplido su deber para con los indios", pues los fundamentos de la evangelización que sobreviven se deben más al trabajo de los curas del frente indiófilo de la Colonia, y no a un esfuerzo de la Iglesia republicana. En este mismo período se sitúa el primer intento de promover en Cusco, a través del trabajo de una congregación religiosa (dominicos), un liceo para indios, pues la educación del indígena era indispensable, tanto para su incorporación plena a la nación como para conjurar los peligros de infiltración de las ideas protestantes y socialistas (1919); este proyecto sólo será realizado por iniciativa personal del obispo en Yucay en 1923.

b) El Congreso Interdiocesano de Acción Social (1921) y el V Sínodo Diocesano (1922)

Resulta particularmente interesante, para entender el espíritu lascasiano que animó el indigenismo eclesiástico de la Iglesia cusqueña en la década del veinte, detenerse a estudiar la realización del Congreso Diocesano de Acción Social (1921). Este esfuerzo de reflexión común de la Iglesia del Sur Andino es promovido por el obispo de Cusco, Mons. Farfán, y secundado por un notable sacerdote diocesano, el canónigo Isaías Vargas. En lugar de sumarse a las pomposas celebraciones del centenario de la independencia, la Iglesia surandina, convocada por Mons. Farfán, se reunirá para reflexionar sobre su quehacer pastoral en la región, a la luz de la encíclica Rerum Novarum (1891); convocatoria a la que respon-

46 Ib., o.c., pp. 140-141. 


\section{IMELDA VEGA-CENTENO B.}

den los obispos de Ayacucho, Puno y Arequipa. El conjunto de los discursos, exposiciones, trabajos de comisiones y actas han sido publicados cuidadosamente por Mons. I. Vargas, y son un fiel reflejo de esta primera reflexión moderna de la Iglesia surandina respecto a sus responsabilidades sociales en la región ${ }^{47}$.

Este congreso reunió también a lo más connotado del medio social, intelectual y político de la diócesis, por ello es muy importante subrayar la actuación del canónigo Isaías Vargas, quien era hombre de Iglesia y de destacada trayectoria intelectual; él tuvo a su cargo el discurso inaugural, y en la sesión de clausura presentó una interesante propuesta a la asamblea, ya que:

"El indígena se agita demandando no sólo que le sean debidamente garantizadas las propiedades agrarias relativamente pequeñas que aún les quedan, sino que le sean devueltas las que les han sido arrebatadas con evidente violación de las leyes de la justicia, con fraude y engaño, a la fuerza, y otras veces pagándoles algún precio no equitativo" 48 .

Ante el estallido social inminente, afirma que está motivado por "la falta de garantías, para los indios, en casi todos sus derechos, en particular el de propiedad, pues este sufre flagrantes violaciones por la rapacidad de los gamonales". La tierra reclamada por los indígenas es la que les asegura el sustento, con la que logran producir algunos productos que llevan al mercado y por los cuales se les paga precios irrisorios. Con esta argumentación "urge a esta Asamblea a que dedique un párrafo siquiera, el más importante tal vez, al derecho de propiedad de los descendientes directos de los autóctonos del Perú"; más aún, sugiere que este reconocimiento del derecho de propiedad del indígena debe estar legalmente garantizado, y que las Cámaras Legislativas tienen que completar su

47 Primer Congreso Interdiocesano de Acción Social, Documentos y ponencias: Homenaje a la Patria en el Primer Centenario de la Independencia, Cusco, Tipografía Americana, 1921.

48 Isaías Vargas, Conferencias y discursos, Cusco, Tipográfica Americana, 1937, pp. 315-317. 


\section{IGLESIA Y CONFLICTOS SOCIALES EN LOS ANDES}

reconocimiento de "patronatos y sindicatos de indios, para la reivindicación de modos justos y legales de los terrenos usurpados por los gamonales" 49 .

Al año siguiente, al convocar al $\mathrm{V}^{\circ}$ Sínodo Diocesano de Cusco, Mons. Farfán afirmará que "es urgente tratar al presente sobre la situación religiosa del indio, y aún sobre aquellas cuestiones indígenas que, en una forma $u$ otra, se rozan con la moral y el servicio religioso" ${ }^{50}$. Los trabajos de este sínodo, cuidadosa y didácticamente publicados, reúnen las 30 constituciones elaboradas en el mismo, $y$, entre ellas, 22 se refieren directamente a la situación socio-pastoral del indígena. Las preocupaciones centrales de la pastoral indígena que emanan de esta asamblea sinodal cusqueña se pueden esquematizar en tres aspectos:

1) Abusos que se cometen contra los indios, frente a los cuales se propone la conformación de hermandades de indios. En la lógica de las propuestas de Mons. Vargas y de la misma Rerum Novarum, estas "hermandades" podrían ser los sindicatos de indios que el canónigo había propuesto en el Congreso Interdiocesano de Acción Social del año anterior. Frente al abuso, la recomendación sinodal es la organización popular.

2) Problemas sociales que aquejan a los indios; sea por causa del abuso de los gamonales o de su propia ignorancia. El sínodo propone y exhorta a la fraternal convivencia entre razas, la enseñanza de sus derechos a los indios y la restitución de lo usurpado, para que pueda tener lugar el sacramento del perdón; nuevamente vemos resurgir esta vieja y fundamental temática lascasiana. Retomando las enseñanzas de la Rerum Novarum se exhorta a respetar el horario de ocho horas de trabajo, y además, ante la reciente creación del Patronato de la Raza Indígena, el sínodo exhorta a los sacerdotes y los fieles a usar ésta nueva instancia en beneficio de los predilectos del Señor.

49 Ib., o.c., p. 317.

${ }^{50}$ Edicto de convocatoria al V ${ }^{\circ}$ Sínodo Diocesano, Cusco, IX/1922. 


\section{IMELDA VEGA-CENTENO B.}

3) Pastoral indigenista. El sínodo hace un recuento minucioso de las necesidades pastorales y de evangelización de los indios, promueve luego una serie de iniciativas $e$ instituciones que puedan llenar los vacíos en la evangelización indígena, advierte sobre los efectos disociadores de la propaganda protestante, promueve los catecismos en quechua como instrumentos útiles para la acción pastoral de los curas de indios; y finalmente hace una propuesta absolutamente nueva, la necesidad de promover el clero indígena. Esta última proposición demuestra que en éste sínodo existió un entendimiento del sacerdocio como servicio evangélico dentro de la cultura y de la comunidad, adelantándose largamente a las intuiciones teológicas del Vaticano II (1965) y a las del Celam en Santo Domingo (1992) ${ }^{51}$.

\section{c) El Patronato de la Raza Indígena presidido por}

Mons. Farfán (1922-1930)

Antes de esquematizar la acción indigenista de Mons. Farfán a través del Patronato de la Raza Indígena, es preciso recordar los elementos constitutivos de su personal acción pastoral indigenista. En el trabajo tantas veces citado estudiamos su historia familiar y su vinculación de parentesco con un líder de la Rebelión Tupamarista. Su propio tupamarismo estará marcado por este recuerdo familiar y por la reivindicación de la calidad del prócer del cacique de Tungasuca y Surinama, José Gabriel Condorcanqui, Tupac Amaru II $^{52}$. Desde los inicios de su formación sacerdotal demostró un interés especial por la situación del indígena, preocupación que alimentó en sus nutridas bibliotecas y que fue desarrollando cada vez más a partir del contacto directo con la realidad del campesino andino a lo largo de sus visitas pastorales, tanto en la diócesis de Huaraz como en la de Cusco. Progresivamente su prédica se va

51 I. Vega-Centeno, 1993, o.c., pp. 146-153.

52 Ib., o.c., pp. 153-178. 


\section{IGLESIA Y CONFLICTOS SOCIALES EN LOS ANDES}

llenando del espíritu lascasiano, volviendo recurrentemente en él los temas de la necesidad restitución al indígena de todo aquello que se le había arrebatado injustamente, la función del obispo como protector de indios y la identificación de éstos con los pobres del evangelio.

Al recibir el nombramiento de presidente de la Junta Departamental del Patronato de la Raza Indígena (1922), Mons. Farfán no se detiene en el cálculo político de si esta institución era un intento del régimen dictatorial para limpiar su imagen abusiva, corrupta y netamente antipopular. Para Mons. Farfán, como para Mons. Olivas Escudero, se trataba de hacer uso de esta nueva instancia institucional, poniéndola objetivamente al servicio de los reclamos indígenas. Por ello, para conformar la Junta Departamental, llama a todos los sectores políticos, sociales e intelectuales de la sociedad cusqueña, reúne a un grupo excepcional de la intelligentia local y la coloca ante la urgencia de dedicarse a exclusividad a la escucha de los reclamos de los indios. Lejos de él la idea de un "comité de notables" que se reuniría cada quince días (según estaba estipulado por ley): la Junta Departamental cusqueña trabaja diez horas diarias y la expectativa que levanta entre los indios es tal que comienza a ser temida y combatida desde las tribunas del diario El Comercio de Cusco.

Aunque ideada en función de ganar prestigio para el Gobierno, la Ley del Patronato de la Raza Indígena y su reglamento ${ }^{53}$ fueron redactados de tal forma que su funcionamiento real era prácticamente imposible: sus objetivos y funciones eran muy amplios, pero además excesivos. Según éstos, las juntas departamentales del Patronato debían proteger al indígena, estudiar su situación, así como analizar el sistema de remuneraciones que debía regir para ellos, ampararlos de los abusos legales, estudiar la creación de industrias, educar e instruir a los indígenas, fomentar sus formas asociativas, propulsar la educación del indio, mediar entre éstos y el Gobierno, y crear asilos y guarderías infantiles para sus hijos. Todo esto añadido a la tarea primera de atender las quejas y

53 El Patronato de la Raza Indígena: Decreto Ley y su Reglamentación, Lima, Tipográfica Americana, 29 de mayo de 1922. 


\section{IMELDA VEGA-CENTENO B.}

los reclamos de los indios, tarea que debía completarse con la tramitación de las mismas hasta las instancias pertinentes, teniendo en cuenta además que todas estas tareas debía cumplirlas la Junta Departamental de forma gratuita ${ }^{54}$.

Sobrecargar de funciones y tareas a las juntas departamentales del Patronato, frente a los agudos conflictos que enfrentaban a los indígenas con el aparato estatal, que defendía a los gamonales, era una sutil manera de vocacionarlo a la inoperancia, o a existir como objeto decorativo, sin función real. Esta institución llamada a la parálisis Mons. Farfán la convierte en un excepcional medio de conocimiento de la situación del campesino surandino, a través de la cual se recopila una importantísima documentación que figura hoy en los archivos departamental y arquidiocesano de Cusco, y que llegarán a formar parte de más del sesenta por ciento de las Actas del Patronato de la Raza Indígena (64\%), del Archivo del Fuero Agrario, a nivel nacional ${ }^{55}$.

El período de revueltas campesinas va desde 1911 hasta 1931; en el Sur Andino la coyuntura entre 1918 y 1923 fue particularmente conflictiva. Sus alcances para cuestionar la vigencia del orden estatal se pueden rastrear no sólo a través del estudio de la creación del Patronato de la Raza Indígena por parte del Gobierno, sino también por el surgimiento de las nuevas ideas sociales, los movimientos político-sociales de la década y, por supuesto, los movimientos y asociaciones pro-indígenas, en todas sus versiones político-sociales, estéticas, literarias y eclesiales. Estas revueltas están ligadas, como dijimos en la introducción, al más importante movimiento social de generación de las ideas político-sociales en el Perú contemporáneo.

Por otro lado, desde los intereses de los gamonales, éstos intentan agruparse para "defenderse de los indios y proteger sus bienes": se forma una liga de hacendados en Arequipa y existen intentos de conformación de otras tantas en Puno, Cusco y Ayacucho. Para algunos voceros del sector gamonal, que relataban con verbo brillante todos los "crímenes y monstruosidades" de las re-

54 Ib., ver análisis más detallado de estos documentos en nuestro; Pedro Pascual, o.c., pp.161-165.

${ }^{55}$ Ver cuadro en I. Vega-Centeno B., 1993, o.c., p.153. 
vueltas campesinas, como El Comercio de Cusco, el "apocalipsis era inminente", describiendo la situación de la región en los mismos términos que los del "gran miedo" posterior a la Gran Rebelión. Desgraciadamente, los hijos de la República persiguieron a los cabecillas indígenas, a los dueños del Perú en el vocabulario de Mons. Farfán, con la misma ceguera y afán de exterminio de la gran represión que vivieron los Andes después del ajusticiamiento de Túpac Amaru II, pero ya no eran los usurpadores extranjeros quienes cometían estos abusos contra los "Cristos mil veces crucificados en las Indias", sino los representantes institucionales de la República.

Ante la avalancha de quejas que provenían de la Junta Departamental del Patronato de la Raza Indígena de Cusco, así como las abundantes de Huancayo, Ayacucho y Huancavelica, el Gobierno comenzó a recortar sus funciones y a entorpecer sus trámites. Esta situación molestó mucho a los colaboradores de Mons. Farfán, los cuales fueron renunciando ante éstas y otras desaveniencias que se produjeron a lo largo de su funcionamiento. Cuando en 1927 se declara ilegal al Comité Pro-Derecho Indígena Tahuantinsuyo, se recortan más aún las funciones del Patronato y las autoridades locales se las ingenian para enfrentar a los más connotados representantes del indigenismo cusqueño (pro-socialistas) con el presidente del Patronato, que era el obispo. Cuando cesa de funcionar, la Junta Departamental cusqueña había cumplido su ciclo, y ésta forma de acción en defensa de los derechos indígenas había dado todo lo que podía dar. Sus límites se hicieron evidentes y sus logros hoy día son innegables ${ }^{56}$.

\section{d) El indigenismo eclesiástico}

El indigenismo eclesiástico de este período, cuya figura más característica es la de Mons. Pedro Pascual Farfán, nace en la huella de la tradición permanente del frente indiófilo y de los obispos protectores de indios. Desde el punto de vista catequético y 


\section{IMELDA VEGA-CENTENO B.}

sacramental, insiste en la necesidad de conversión al indio para poder entenderlo y ser capaces de anunciarle el evangelio desde su propia cultura; consecuencia de esta conversión al indio es la necesidad de restitución de todo lo que abusivamente le ha sido arrebatado, no sólo reconociendo que es el dueño original del Perú, sino que es dueño de su propia historia. Los escritos de Farfán trasuntan una mezcla de preocupación pastoral del protector de indios, profecía y temor, de un estallido que tardó en llegar, pero que se anunciaba cruel y profundamente injusto.

Sacerdote por vocación, servidor de los más pobres, Pedro Pascual Farfán de los Godos es un fiel seguidor del frente indiófilo, empapado del espíritu lascasiano más allá de la letra, por eso es capaz de reconocer en los indios pobres a los pobres según el evangelio y se proclama obispo de indios, protector de indios, defensor de los mismos contra las campañas de desindianización del país, que implicaban su exterminio. Desde el punto de vista de su intervención social, podríamos decir que la acción pastoral indigenista de Mons. Farfán se inscribe en las tres corrientes de acción descritas por Tamayo Herrera, por su insistencia en los proyectos de educación y granjas-escuela para indios, y el logro de la granja de Yucay podría caracterizarse dentro de la corriente pedagógica. Por su acción documental y de tramitación de quejas de los indios dentro del Patronato de la Raza Indígena, podríamos situarlo dentro de la corriente legislativa, ya que sabemos que además intervino directamente en la discusión de determinadas medidas legales tomadas por el Parlamento. Y, finalmente, por la promoción de normas tutelares y su prédica incansable de justicia, podemos situarlo dentro de la corriente social. Aunque su opción evangélica y los fundamentos teológico-doctrinales para su acción escapen a toda esta clasificación y nos conduzcan hacia referentes de fe que no son alcanzables por el análisis sociológico ${ }^{57}$. 


\section{PERMANENCIAS: EL ESPÍRITU LASCASIANO Y LA PASTORAL RURAL}

Sostenemos que el espíritu lascasiano que animó al frente indiófilo no solamente se reactivó en la tensa coyuntura de las tres primeras décadas de este siglo, sino que, al formar parte de los fundamentos doctrinales básicos de la vocación cristiana, permanece latente a lo largo de toda la vida de la Iglesia en los Andes. Su reactivación estará relacionada con determinadas coyunturas sociales y politicas que darán el marco contextual para su actualidad y permanente vigencia, pero, sobre todo, dicha reactivación es posible a través de la actuación de representantes de Iglesia sensibles y permeables a las enseñanzas evangélicas, los mismos que son capaces de hacer histórica su caridad a través de la defensa del derecho de los pobres, los indios.

La última etapa de acción de las enseñanzas del frente indiófilo y de su espíritu lascasiano podemos rastrearla desde 1955, cuando, bajo la influencia de los filósofos sociales franceses, en el Primer Congreso Nacional de la Acción Católica, un delegado del Sur Andino exige que no se olviden dos tareas: "Comprender y solucionar el problema del indio como un gran problema nacional no resuelto". Muy poco tiempo después, la carta pastoral colectiva de los obispos peruanos sobre las Exigencias del catolicismo social en el Perú dirá que es una tarea de los cristianos el "educar al indio y realizar una reforma agraria justa" (1958). Al año siguiente, en la Primera Semana Social del Perú, C. Arróspide de la Flor planteará la necesidad de "conocer a los indios en sus diferencias culturales y propender la promoción cultural del indígena", renovando los criterios para el acercamiento a la cuestión indígena, más allá de su versión economicista ${ }^{58}$.

Con la publicación de la encíclica Mater et magistra de Juan XXIII, las iniciativas eclesiales y pastorales respecto a la problemática rural e indígena tendrán un renovado auge. En 1960 se funda la Juventud Agrícola y Rural Católica, la misma que, a través de sus dos etapas de funcionamiento, ha venido formando hasta hoy dirigentes laicos cristianos en el medio rural y muy en particular en

58 J. Dammert, o.c., pp. 171-173. 
IMELDA VEGA-CENTENO B.

el Sur Andino. En 1962, en varias sedes episcopales, se funda el Instituto de Educación Rural (Huaura-Sayán, Cajamarca, Juli, Ayaviri), el mismo que, bajo la inspiración del obispo chileno M.Larraín, fue un paso importante en la formación y capacitación de los laicos del medio rural. Luego de la "Ley de Bases de la Reforma Agraria" (1962), el arzobispo de Cusco realizará una "reforma agraria" dentro de las propiedades de la Iglesia. Posteriormente, en el marco de la Ley de Reforma Agraria del Gobierno militar (1969), una carta pastoral colectiva del episcopado peruano reconoce su necesidad y urge para que ésta se cumpla a partir de una serie de exigencias éticas.

En 1970 se funda el Instituto de Pastoral Andina, que es un órgano de reflexión, formación, intervención social y de reflexión pastoral de los obispos del Sur Andino; ese mismo año se inician las rondas campesinas en Cajamarca, apoyadas por el obispo, como una forma de defensa campesina frente al flagelo del abigeato. Posteriormente, esta organización campesina se generalizará en el país y, tanto en el altiplano surandino como en Cajamarca y Ayacucho, servirá para detener el avance del terrorismo de las décadas del 80 y 90. El Centro de Estudios Rurales Andinos Bartolomé de Las Casas, fundado en 1974, retomará las iniciativas pedagógicas, tutelares y de estudio de la realidad surandina que sus predecesores dominicos del frente indiófilo habían iniciado, reinsertándose en las huellas del más ilustre fraile dominico que hayan conocido las Indias, fray Bartolomé de Las Casas.

Si la denominación de neo-indigenismo ${ }^{59}$ a los actuales proyectos de pastoral rural e intervención social de instituciones eclesiales del Sur Andino no nos parece correcta, reconocemos en ella sin embargo cierta validez en su intuición. El trabajo del Instituto de Pastoral Andina o del Centro Bartolomé de Las Casas de Cusco no puede ser clasificado como neo-indigenismo, si es que se identifica el indigenismo únicamente en su vertiente político-social, pues "el indigenismo como discurso ideológico es una lectura de clase que intenta definir las estructuras de la sociedad global en términos culturales, integrando el pasado indígena como posibilidad de 


\section{IGLESIA Y CONFLICTOS SOCIALES EN LOS ANDES}

expresión y de condicionamiento para el futuro de la 'nación peruana', el movimiento propugnaba una integración del elemento indígena en la lectura presentada por los intelectuales cusqueñistas que intentaban producir un discurso, y generalizarlo o imponerlo de alguna manera al conjunto de la nación. Porque una de las finalidades del discurso ideológico es precisamente imponer su lógica a la lectura de las otras clases ${ }^{60}$.

El trabajo de dichas instituciones de Iglesia, así como múltiples experiencias pastorales y sociales a lo largo de todo el Perú rural, no es la prolongación del movimiento indigenista en su versión político-social, sino que se inscribe en otra tradición de pensamiento, está entroncado con otro sistema de sentido: prolongación del frente indiófilo y del espíritu lascasiano que a comienzos de siglo animó al indigenismo eclesiástico y que en el post-Vaticano II reactivará los fundamentos evangélicos de la acción pastoral en el campo, dando un nuevo impulso a una pastoral rural comprometida con la historia del pueblo pobre en los Andes; con los indios, predilectos del Señor, heredad y pupila de los ojos de los obispos, quienes en los Andes son, por vocación y definición, defensores de indios, obispos de indios.

Tal como hemos demostrado, el espíritu lascasiano se difunde más allá de la letra (si se tuvo acceso o no a los libros de Las Casas) porque sus fundamentos están en el evangelio y en la más tradicional doctrina cristiana sobre la restitución, en el anuncio del evangelio a los pobres, predilectos del Señor. Estos fundamentos doctrinales son permanentes y no dependen de las modas intelectuales ni de los proyectos políticos hegemónicos; estos fundamentos propios de la Iglesia en su compromiso con el destino histórico de los indios son los elementos que, sociológicamente, le otorgan autonomía. Por su parte, la correlación de fuerzas sociales en conflicto dentro de la coyuntura serán los elementos que relativizarán dicha autonomía. La capacidad de determinados agentes eclesiales de acrecentar su autonomía relativa dependerá justamente de la posibilidad de llevar hasta las últimas consecuencias su funda-

60 Henrique O. Urbano, "Discurso mítico y discurso utópico en los Andes", en Allpanchis No 10, Cusco, IPA, 1977, p. 13. 


\section{IMELDA VEGA-CENTENO B.}

mentación propia: el anuncio del evangelio, la inversión de la historia provocada por Cristo, poniéndose al servicio de los indios, siendo protectores de indios, restituyéndoles no sólo lo usurpado sino el derecho a ser señores de su propia historia y sobre todo mostrando que el Reino de los Cielos está cerca, ya que los pobres son evangelizados" (Lc 4,18-19) ${ }^{61}$.

Si para los participantes del movimiento de renovación cultural y estética del "indigenismo-2" había que rescatar, hacer justicia con el indígena, salvándolo del olvido y la exclusión, para los herederos del frente indiófilo, del espíritu lascasiano y del indigenismo eclesiástico, de lo que se trata es de reconocer al indígena no sólo como dueño del Perú (Mons. Farfán), sino como dueño de su propia historia y de sus organizaciones representativas (Mons. Vargas), con una cultura diferente que plantea retos teológicos y pastorales completamente nuevos ( $V^{\circ}$ Sínodo Cusquense, I Semana Social del Perú). Estas son las viejas novedades que replantea aún la encarnación del espíritu lascasiano en el Perú, en el umbral del tercer milenio.

${ }^{61}$ Para el análisis de la autonomía relativa de la Iglesia, véase Imelda VegaCenteno B., Campo político, campo religioso, luchas populares y coyuntura en el Perú: estudio de un conflicto laboral en 1971, Lovaina, Institut de Sciences Politiques et Sociales, UCL, 1976. 